\title{
A STUDY ON THE SELF-ESTEEM LEVEL AMONG THE STUDENTS OF COLLEGE OF HOME SCIENCE
}

\section{T. ARUNA BHARATHI}

Teaching Associate, Department of HDFS, C.H. Sc, PJTSAU, Hyderabad, India

ABSTRACT
A study was conducted to analyze the self-esteem of the students of College of Home Science, PJTSAU,
Hyderabad, Telangana state, India. For studying the self-esteem level of the students, Rosenberg Self-esteem scale
(1965) was used. Findings of this study had revealed that, the 55\% (higher percentage) of the students had medium self-
esteem, whereas the remaining 45 percentage of students were with high self-esteem. We strongly believe that, this study
will help the parents and teachers, to maintain the self-esteem in optimum level among the college students.
KEYWORDS: Self-Esteem, Adolescent, Home Science, Education \& College

Received: Aug 20, 2017; Accepted: Sep 11, 2017; Published: Oct 09, 2017; Paper Id.: IJESROCT201711

\section{INTRODUCTION}

Education is a very important tool for expanding student's mind. It will help in exposing every student to lot of opportunities, topics, people and experiences. Due to education, students grow and develop in many areas including analytical awareness, decision-making, creative expression, reasoning, verbal expression and many more. Students get matured and develop, into responsible and independent adults, during their college days.

The sense of identity, self-concept and self-esteem is developed by the students, during their college days typically. It is the time when the students themselves figure out what the life is all about. They try to make lot of friends and be "accepted" by peers. Adolescence is one of the most fascinating periods of development in the life span of human, which links childhood with adulthood. The thoughts of an adolescent would always be idealistic and abstract. There is a long worrying history, about the adolescents' growth and the way how they will 'turn out'. 'Storm -and-stress' view was proposed by G. Stanley Hall in 1904, in which he proposed that the adolescence is a turbulent time period, in which the adolescents experience conflict and mood swings. Nevertheless, the studies of Daniel Offer and his colleagues (1988), on adolescents' self-images in the United States, Bangladesh, Australia, Israel, Hungary, Japan, Turkey, Taiwan, Italy and West Germany revealed that, at least 73 percent of the students showed healthy self-image.

In recent days, self-esteem is one of the significant research topics in psychology. Research of Naderi, Abdullah, Aizan, Sharir\& Kumar (2009) has documented the significant role of high self-esteem, in achieving academic results and in developing social, and personal responsibility. Studies have been conducted by the researches, on self-esteem in relation with many other variables like drug abuse, violence, relationships, bullying and academic achievement (Jonsson, 2006).

What is the reason behind the self-esteem study on college students?

The reality is the life is not always a bed of roses. This is the reality of universe and this should be 
understood by everyone. In the life process, the human beings encounter obstacles and hurdles right, from the birth to death. These challenges could be psychological, physical, social, emotional, spiritual and economical. Among these, some of the obstacles could be perceived or imagined by the college students, whereas some of the obstacles could have been experienced in real. When their expectations are not met, and when their needs are not satisfied, they feel hurt, angry, disappointed, emotionally depressed and upset, or hostile towards other. This type of attitude or behavior, leads to the development of low self-esteem among the students, which in turn is likely to develop adjustment problems among them. Lack of adjustment with self, family, community and the world may also develop emotional, mental and psychosomatic disorders. They also become drug addicts, alcoholics and delinquents. It also leads them into the activities like property damage, attempt to suicide and attempt to murder, meet frequent accidents, family conflicts, marital disharmony and problem in adaptation, with the social system and may also lead them in joining terrorists or militants group.

Self-esteem plays a crucial role and acts, as a keystone to maintain positive attitude towards living. It affects the thinking ability of every human being. It plays a very important role, in the life of every human and has direct influence on their behavior, thinking and how they relate themselves to other people (Perera, 2007).

William James (1842-1910), an American psychologist was the first to use the term, 'self-esteem'. He conducted the study on self-esteem based on introspection. William James said that, self-esteem is a dynamic process and an effective phenomenon. It is said to be affected by the successes and failures faced by the individuals and thus, subjected to enhancement (Sue \& Jo, n.d.). Individuals with high self-esteem indicate self-respect and consider oneself worthy, but not egoistic (Rosenberg, 1965). On contrary, individuals with low self-esteem show self-dissatisfaction, self-rejection and selfcontempt (Mansor, 1999). People with high self-esteem can be found to be more willing, to speak up in group and they can openly criticize the approach of a group. Leadership qualities do not come from self-esteem directly, but it has indirect effects on the individuals' skills. When compared to low self-esteem, people with high self-esteem show stronger in-group favoritism. This may increase discrimination and prejudice.

The problem with low self-esteem students is that, they underestimate themselves and feel undeserved to be successful (Linda et al 1984). Low self-esteem also shows deep emotional effects on the students. They fail to take right decisions at right time. Moreover, they have a feeling of less control over their lives and they show very low confidence.

Low self-esteem also shows a significant effect on the individual relationships. When there is problem in liking themselves, it becomes very difficult for them to like others and to share their views with others. People can love others, only when they love themselves. When there is difficulty in self-love, acceptance of others love and affection would be difficult.

Lack of self-esteem affects our work and success as well. It leads to lack of confidence and motivation to success in life and at work. If the students have low self-esteem and if they do not feel good about themselves, it may affect their projects. They may leave their projects unfinished. Those students will also be not interested in initiating, organizing and managing group activities. Some of them would engage themselves into drinking, drug addiction and immerse into the life of party just to cover their low self-esteem. Some others would always be angry and stay isolated, and show their mood out on others. According to Donovan et al., 1984, these people are actually very sad inside and they need somebody's encouragement and support, to stay away from these destructive ways.

As the self-esteem is very important, it made the researchers to conduct a study on the self-esteem level among 
the students of College of Home Science, PJTSAU, Hyderabad, Telangana state, India.

Home science is a study of integrated fields. It provides systematic and scientific knowledge on various aspects of living in a family. It is a field of interdisciplinary faculty of science. It helps the students by preparing and developing them with the multiple options of vocation and career.

The first All Indian Women's Conference was held in 1932 at Lady Irwin College, New Delhi. During this conference, Home Science was defined, "as a practical science, which makes the students to lead his family life successfully and solve social and economic problems easily and well."

Home science is the science of home, which includes everything that concerns the person, family members, home and resources. It is the study for "better living" and the core of this subject is the family ecosystem. It also educates about the reciprocal relationships between the families, its nature and the man-made environments. The main aim of this course is to attain maximum satisfaction, for that person and the family members. This could be attained through the scientific and efficient usage of the resources. The student gains knowledge on all the scientific procedures, that make a home beautiful.

Home science is also an integration of the application of humanities and various sciences. This course improves family environment, nutrition, child development and develops the skills on resource management. The knowledge on Home Science not only, helps in improving the quality of life, but also in better use of available resources to attain maximum satisfaction and good returns.

\section{SIGNIFICANCE OF THE STUDY}

- This study was conducted, with an aim to identify the self-esteem level among the students of College of Home Science, PJTSAU, Hyderabad.

- The results from this study help the teachers, parents and the administrators to address the problems, and to maintain the required level of self-esteem among the college students.

- This study may also help the students to understand the significance of maintaining self-esteem, its role in motivating the individuals internally and for triggering them to work in order to achieve success and experience success, throughout their lives.

\section{OBJECTIVES}

To identify the level of self-esteem, among the college students studying in the College of Home Science, PJTSAU, Hyderabad, Telangana State.

\section{METHODOLOGY}

\section{Sample Selection}

A group of 20 college girls were selected as total sample for the study from the College of Home Science, PJTSAU, Hyderabad, Telangana State, India.

Tool Used

To study the level of self-esteem among the college students, Rosenberg self- esteem scale (1965) was used. 


\section{Data Collection}

The selection of college students was done by meeting the students in person and explaining the purpose of the study to the respondents. For the purpose of studying, the self-esteem of the students of College of Home Science Rosenberg Self- esteem scale (1965) was used.

\section{RESULTS AND DISCUSSIONS}

Table 1: Level of Self-Esteem among the Students of College of Home Science $\mathrm{N}=40$

\begin{tabular}{|l|c|c|}
\hline Interpretation & Frequency & Percentage \\
\hline Low & --- & \\
\hline Medium & 22 & 55 \\
\hline High & 18 & 45 \\
\hline
\end{tabular}

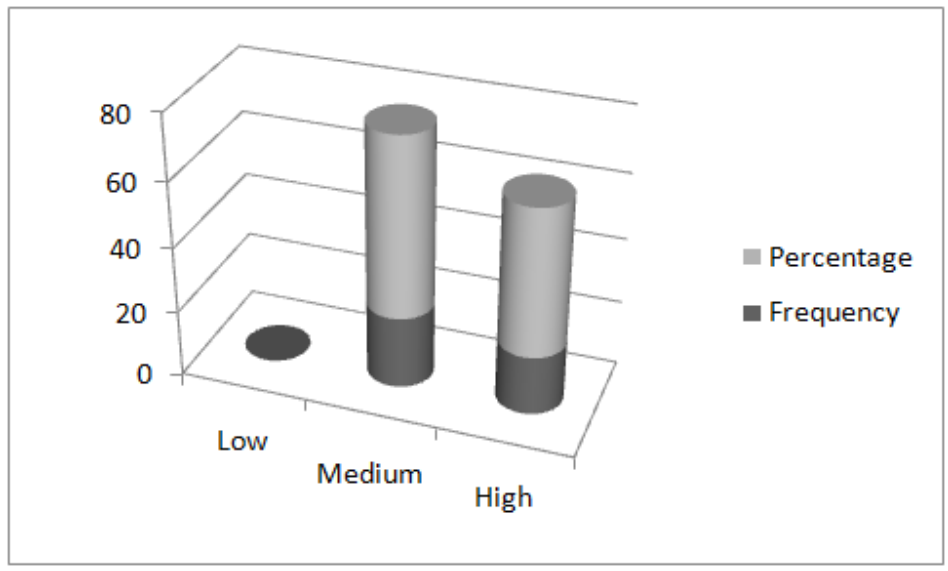

Figure 1: Level of Self-Esteem among the Students of College of Home Science

The results on the studies (Table 1) conducted on the self-esteem, among the college students of Home Science college students revealed that, higher percentage of the students $(55 \%)$ had medium self-esteem. There are possibilities that these medium self-esteem students may shift to low self-esteem, when the situations in their lives worsens. This result is in par with the study of Blyth, Simmons and Carlton-Ford 1983; and Simmons, Rosenberg, and Rosenberg 1973. With the self-esteem studies, gender patterns have also been found. When the studies were conducted in the United States, during 1970s and 1980s, the results revealed that, the self-concept of the girls is more vulnerable during their early adolescence, particularly in urban areas. In addition to this, a meta-analysis investigating self-esteem research conducted in Western industrialized countries confirmed that, the self-esteem of the adolescent girls is generally lower than the boys' self-esteem. The research results reveal that, low self-esteem affects all the important facets of life. It directly affects an individual's confidence, which in-turn affects the students' performance in academics, their ability to build up and maintain inter personal relationships. This would in turn lead to social problems, such as driving them into depression and suicide attempts/eating disorder/drug abuse/indulging into crime and violence/misconduct by teenage girls, leading to pregnancy (MyOUM, 2007). Furthermore, it has been observed that, the low-esteem is closely related to depression and self-esteem. James Battle (1980) was the first to document the close link between depression and self-esteem. He found that, when there is rise in depression, there would be decline in self-esteem (Reasoner, n.d.). The study also says that, the people with low self-esteem sees life from negative perspective and considers that, they are worthless and has the feeling of pessimism. 
They may also feel inferior to others and thinks that, whatever they do is not right and others will criticize them for what they do (Davmac, 2009). Low self-esteem along with pessimistic feelings, together with other factors make people vulnerable to depression, which invokes response towards depression, for example, attempt to suicide (Corpcom, 2010).

It's not that, the people with low self-esteem do not have any goals. They have desires and high aspirations. But, they show laziness and do not try to achieve their goals. They also underestimate their qualities and abilities, and fail to achieve. They prefer staying in their comfort zone, since they are afraid of meeting new people and trying out new things. They also do not have the tendency, to accept any form of critics and indulge into argument with others, when they fail in any situation.

Malaysian Employers Federation (2009) says that, the problems faced by the employers while hiring fresh graduates are related to lack in self-confidence. This is especially in mixing with soft skills, business community and communication ability. The reason behind all the setbacks is due to lack in self-esteem, among the fresh graduates. To come out of low self-esteem, the students should find ways for self-enrichment and should take efforts in skill improvement, in order to get high self-esteem. After developing self-esteem, they should turn their attention on what they want to do. When they start focusing on what they want in their lives, the negative thinking will stop. When the negative thinking stops, the positive attraction begins. At that moment, the feeling will change from bad to good. This is one of the good ways for improving self-esteem. According to Rogers, an individual can develop the positive sense of self, when he grows up in an environment of unconditional love. Unconditional love is something like holding on vibration alignment, no matter what is going on around you. It makes you to feel good, praise and appreciate something. The study has revealed that, 45 percent of Home Science college students have high self-esteem. Home Science is a course that teaches the students, how to get along with each other and it also develops problem solving skills, within the family and outside the family. It develops the ways of improving one's knowledge, emotional intelligence and skills. It helps the people to think in a conscious way and equips them with the abilities, required for creative living and responsibility. High self-esteem effectively energizes the student's available resources, than the low self-esteem students. High self-esteem builds inner strength and builds confidence, that leads to happiness.

\section{CONCLUSIONS}

The study results revealed that, higher percent (55\%) of Home Science college students had medium self-esteem and lower percent $(45 \%)$ had high self-esteem. Self-esteem is the perception of an individual's feelings. Students with medium self-esteem should find better ways for self-enrichment, and put lot of efforts to improve one's high self-esteem. This can be done by setting goals, based on one's own strengths and abilities. They should always think positively and should never compare themselves with others. Students with medium self-esteem need some change in their attitudes. They should develop confidence; accept reality and need to accept self and others. It is advisable for the medium selfesteem students, to consult counselors for solving problems, understand reality, and helping themselves in achieving selfdevelopment, good health, happiness and productivity. Colleges should conduct training programs for the students, on capacity building and personality development to understand them in first place. These training programs will also help them to understand the significance of self-esteem in their life and to understand that, high self-esteem leads to satisfaction and happiness. The college authorities should also organize workshops on the improvement of life skills of the students. This will enhance their skills and make them ready to face the world and challenging situations, throughout their lives. 


\section{REFERENCES}

1. Blyth DA, Simmons RG, Carlton-Ford S. The adjustment of early adolescents to school transitions. Journal of Early Adolescence. 1983; 3:105-120.

2. Donovan, Mary Ellen \&Tschirhart Sanford, Linda. (1984). Women and Self-Esteem. Viking Penguin Inc. New York.

3. DurmuşUmmet (2014). Self esteem among college students: a study of satisfaction of basic psychological needs and some variables.1877-0428@2015, www.sciencedirect.com.

4. James Battle (1980).Relationship between Self-Esteem and Depression among High School Students, 51. http://journals.sagepub.com/doi/pdf/10.2466/pms.1980.51.1.157

5. John W. Santrock. (2011).Life-span development,(13 ${ }^{\text {th }}$ ed).McGraw Hill Education (India)Private Limited.

6. Maheswari.R, \& Maheswari.K.(2016). A Study on Self-Esteem among the college students. IOSR Journal of Humanities and Social Science (IOSR-JHSS), 21, www.iosrjournals.org.

7. M. Mansor.M.(1999). Influence of ethnicity in optimizing antiepileptic drug dosing: a comparison of Malay, Chinese and Indian populations in Malaysia, http://eprints.nottingham.ac.uk/12787/1/267059.pdf

8. Margaret Zoller Booth and Jean M. Gerard.Self-esteem and academic achievement: a comparative study of adolescent students in England and the United States https://www.ncbi.nlm.nih.gov/pmc/articles/PMC3779915/

9. Naderi, H. Abdullah, R., Tengku-Aizan, H., Sharir, J. \& Kumar, V. (2009). Intelligence, creativity and gender as predictors of achievement among undergraduate students. Journal of American Science, 5 (3), 8-19.

10. Rosenberg, M. (1965). Society and the adolescent self-image. Princeton, NJ: Princeton University Press.

11. Simmons $R G$, Rosenberg F, Rosenberg M (1973). Disturbance in the self-image at adolescence. American Sociological Review, 38(no. 5):553-568.

12. http://www.cesdp.nmhu.edu/youth-programs/docs/importance-of-college.pdf

13. http://cms.gcg11.ac.in/attachments/article/86/Meaning\%20and\%20importance\%20of\%20Home\%20Science\%20(1).pdf

14. http://www.preservearticles.com/2011100814970/what-is-the-importance-of-study-of-home-science-in-daily-life.html

15. http://www.homescienceeducation.com/definition-of-home-science.html

16. http://www.mapmytalent.in/career/home-science

17. https://www.ukessays.com/essays/psychology/a-study-of-self-esteem-of-college-students-psychology-essay.php

18. http://www.vepsy.com/communication/book7/9_9_Jonsson.pdf

19. http://www.eurojournals.com/ajsr_3_03.pdf

20. http://www.tqm.com.my/article11.htm

21. http://ehlt.flinders.edu.au/education/DLiT/1999/WEBNOTES/website/homepage.htm 